\title{
El concejo de Zamora en el siglo xV: Monopolio y oligarquización del poder municipal. Aproximación al proceso*
}

Manuel F. Ladero Quesada **

La tendencia de la Corona al control de los gobiernos urbanos llega a uno de sus puntos culminantes con Alfonso XI y para Zamora tiene su plasmación clara en la Ordenanza de 1342, culminando un largo proceso iniciado muchos años antes, institucionaliza la presencia de un órgano cerrado al frente del gobierno de la ciudad. Este modelo inicial con el paso del tiempo irá progresivamente consagrando una oligarquización muy acentuada del gobierno urbano, de forma tal que sobre la oligarquía urbana, de cuyas luchas es fruto el regimiento como factor equilibrador, se va a superponer un reducido grupo de individuos o familias - surgidos, no lo olvidemos, de esa oligarquía - que irán acumulando en sí un poder y una prepotencia sobre el conjunto del cuerpo social que, de forma inevitable, provocarán, a lo largo de todo el siglo, una importante conflictividad derivada del intento de todos los sectores ciudadanos por recortar sus atribuciones o, por lo menos, impedir sus arbitrariedades.

El siglo $x v$ está jalonado de indicios documentales que constatan este malestar social. Ya en $1390^{\prime}$ Juan I, a petición de los vecinos y moradores de la ciudad uassi de parte de cavalleros como de parte del dicho conçejo", ordena que todos los integrantes del regimiento respeten la ordenanza de Alfonso XI en lo relativo a que no desempeñasen más oficio que el propio de regidor, permitiendo que el resto de los oficios del

\footnotetext{
* Comunicación presentada al I Congreso de H. ${ }^{a}$ de Zamora. Zamora. marzo 1988

* Universidad Nacional de Educación a Distancia.

' AMZ. Libro Tumbo de las Escrituras de la ciudad de Zamora (siglos XIV-Xvi). f. 94.
} 
concejo se repartiese entre los demás vecinos de la ciudad de acuerdo con sus privilegios ${ }^{2}$.

En cierto modo, en la carta del monarca parece advertirse la existencia, en estos primeros años de funcionamiento del regimiento cerrado, de un aparente vacío legal $o$, por lo menos, una cierta imprecisión en la acción regia sobre el gobierno de los municipios; así, Juan I señala: "e que se reçelan (los habitantes de Zamora) que non querededes cunplir la dicha nuestra carta que nos vos dimos a vos los dichos regidores por la qual mandamos a los cavalleros e escuderos e omes buenos de la dicha çibdad que non contendiesen con vos los dichos regidores en pleyto sobre rason de los dichos ofiçios fasta que nos no lo viesemos e daclarasemos sobrello to que nuestra merçet fuese". Este texto parece querer dar a entender que, en un primer momento, cuando se plantea el conflicto el monarca no tiene una postura definida sobre si debe permitir a los regidores acaparar cargos, lo que supondría un sustancial acrecentamiento de su poder, o por el contrario, limitar dicha acumulación.

Pero las disputas no proceden exclusivamente de los intentos hegemónicos de los regidores, también ellos se defienden vigorosamente de las tentativas de recortar sus atribuciones. Cinco años antes, en 1385, Juan $I^{3}$ se ve obligado a intervenir en un asunto que es de vital importancia para el mantenimiento de la autoridad de los integrantes del regimiento. En efecto, parece que por parte de los vecinos de la ciudad, pensamos especialmente en sectores de la oligarquía marginados por diferentes motivos del regimiento, cuando se producía alguna vacante de regidor o escribano intentaban soslayar el mecanismo establecido para la elección del sustituto, es decir, mediante una petición elevada por el consistorio formalmente constituido al monarca, haciendo directamente la petición al rey ${ }^{4}$.

${ }^{2}$ Ibídem, “E agora saver que es nuestra merçed que vos los dichos regidores e los otros regidores que fueren de aqui adelante en la dicha çibdad que no ayades otros ofiçios algunos en la dicha çibdad fuera del dicho regimiento e que los ayan los otros vesinos e moradores de la dicha çibdad que no sean de vos los dichos regidores".

${ }^{3}$ AMZ. Legajo 16, doc. 4. Publicado por E. Fernández Prieto, Nobleza de Zamora. Madrid, CSIC, 1953, págs. 140-141.

${ }^{4}$ Ibídem, «que quando algunos ofiçios vacan en la dicha çibdad asy de los regidores como de las escrivanias que aquellas personas que los entienden ganar que andan aperçibiendo a sus amigos fuera del consystorio de que les den sus bozes para los dichos ofiçios de lo qual acaesçen muchas vegadas e contiendas e que nos pediades por merçed que quando de aqui adelante dichos ofiçios vacaren en la dicha çibdad que los que mostraren ante nos petiçiones que sean dadas en consystorio en el logar que es acostunbrado en la dicha çibdad para se dar las tales petiçiones que estas tales mandasemos que valiesen 
La actitud regia ante esta situación es clara, hubiera sido absolutamente contradictorio con la política desarrollada por la monarquía castellana desde Alfonso XI - basada en el control de las ciudades a través de un reducido grupo de oligarcas urbanos instalados en el regimientoel permitir que elementos ajenos a este grupo interviniesen en el gobierno marginando la autoridad y las prerrogativas del cabildo de regidores. El delicado equilibrio entre la monarquía y las ciudades, que se basa en una cierta autonomía urbana bajo el control de ese pequeño sector dirigente, quedaria roto al permitir el reavivamiento de las disputas entre las distintas facciones de la oligarquía urbana que, sin haber desaparecido, al menos ahora se circunscriben al ámbito interno del propio regimiento.

En todo caso, lo que este documento revela es el hecho de que, a pesar de los cuarenta años transcurridos desde su instalación, el sistema de regimiento, aunque ya cuenta con una solida base, tiene todavía muchas lagunas en su funcionamiento, fundamentalmente porque los regidores no tienen, a diferencia de lo que ocurrirá más adelante, en sus manos todos los mecanismos necesarios para ejercer el poder municipal de forma casi absoluta y para ello será preciso que la legislación emanada de los reyes se vaya completando. De ahí que Juan I comprenda que para que el sistema pueda ser eficaz, al menos en Zamora, determinadas prerrogativas regias, como el nombramiento directo de los cargos concejiles, deben desaparecer o por lo menos mitigarse, de forma tal que los miembros del regimiento tengan una mayor capacidad de actuación en ese terreno.

Sin embargo, la solución de este conflicto de competencias no va a resultar tan sencillo y el problema se arrastrará a lo largo de bastantes años. En unas ocasiones las necesidades de la política real, otras veces la presión de determinados sectores de la oligarquia urbana y también, algo que no cabe despreciar absolutamente, la fuerza de la costumbre ${ }^{5}$, hicieron que los monarcas nombrasen directamente numerosos oficios de los gobiernos municipales zamoranos, tarea que teóricamente no les correspondia, lo que fue motivo constante de alteraciones y pleitos.

\footnotetext{
e diesemos los ofiçios a las personas en tales petiçiones contenidas e que quando de otra guisa fueren dadas non valiesen, saver que nos plaçe e es nuestra merçed...".

${ }_{5}^{5}$ Parece claro que a lo largo de la segunda mitad del siglo XIV, el procedimiento de nombramiento directo por parte de los monarcas era lo habitual. Asi, en el mismo documento se lee: "Pero que es nuestra merçed que la petiçion que vos los dichos regidores diste por nuestro ruego y mandado a Bartolomé Rodrigues nuestro escrivano que aya el primer ofiçio que vacare ay en la dicha çibdad de parte del conçejo que vala pues en aquel tjenpo se usava asy".
} 
Será en el reinado de Juan II, en 1427, cuando comiencen a adoptarse medidas tendentes a clarificar la cuestión. En primer lugar, se concede definitivamente el privilegio de designar los oficios a la ciudad ${ }^{6}$. En segundo término, se especifica cuál ha de ser el sistema por el que ha de realizarse la elección, que va a corresponder exclusivamente a los regidores reunidos en consistorio, los cuales nombrarán tres personas para el oficio vacante - nos referimos solamente a regidores y escribanos- y enviarán sus nombres al rey que será el encargado de designar a uno de los tres propuestos ${ }^{7}$.

Este modelo será el que presida la elección de los cargos concejiles a lo largo de todo el siglo $\mathrm{xV}$; sin embargo, se seguirán produciendo numerosos incumplimientos, especialmente durante el mandato de los Reyes Católicos que, con cierta frecuencia, efectuarán designaciones directas lo que originará protestas y litigios entre las personas directamente implicadas ${ }^{8}$.

Al margen de estos oficios para los que, de un modo $u$ otro, era necesario el refrendo o la participación del monarca en su elección, el conflicto permanente que enfrentará al cabildo de regidores con el resto de la oligarquía urbana, agrupada en el "gremio de cavalleros e hijosdalgo", una vez superadas las luchas por el poder político de épocas anteriores, será la elección y el reparto de los numerosos oficios y cargos que integran el «funcionariado concejil», cuya designación es de exclusiva competencia de la ciudad. La larga duración de las disputas así como el encono de unos y otros por defender sus intereses, nos hablan bien a las claras de la importancia, no sólo honorífica, de estos escalones inferiores de la administración municipal. Existen noticias de numerosos intentos de concordia a lo largo de todo el siglo xv, hasta llegar al acuerdo definitivo - al menos para el periodo objeto de nuestro estudiodel año 1499, en el que se recogen acuerdos anteriores y se perfila de un modo definitivo el reparto de competencias y prioridades en el nom-

${ }^{5}$ Es el mismo documento que el de la nota 3. AMZ. Legajo 16, doc. 17, $f$. 10. Confirmación fechada el 10 de octubre de 1446.

7 Ibidem.

${ }^{8}$ Por ejemplo, en 1483 Cristóbal de Ortega y Juan de Mazariegos están en pleito por un oficio de regidor de Zamora (AGS. R.G.S. 30-X-1483, f. 135). Entre 1490 y 1491 se desarrolla un largo pleito por una escribania entre Pedro Orejón, designado por el concejo, y Alonso Álvarez, designado directamente por los monarcas; al final será el primero quien hará valer sus derechos y ocupará el oficio. (AGS. R.G.S. 21-VII-1491, f. 14. Confirmación definitiva de la sentencia. En la misma sección se encuentran numerosos documentos donde se puede seguir paso a paso el pleito: $11-1491$, fols. 76,77 y 178 entre otros.) 
bramiento de los oficios concejiles, mediante una normativa muy completa.

En el Libro Tumbo de las Escrituras de la ciudad de Zamora ${ }^{9}$ aparecen contenidos varios documentos que jalonan todo el proceso. En primer lugar, la Ordenanza de Alfonso XI y la carta de Juan I de 1390, a las que ya nos hemos referido, que señalan la prohibición de que los regidores desempeñen otros oficios del concejo. A continuación, la sentencia dictada por el corregidor doctor Ruy García de Villalpando, en el año 1419 , que, en esencia, respeta lo contenido en los documentos anteriores y que además desciende a aclarar varios detalles concretos de suma importancia:

1. Que los hombres de los regidores - "Que con ellos biven o dellos an tierra o mantenimiento o acostamiento o son sus allegados 0 apaniaguados»- pueden ocupar oficios del concejo siempre que estén capacitados para ello y reúnan ciertos requisitos como, por ejemplo, el estar casados o tener casa en la jurisdicción de la ciudad, bien sea propia o de alquiler.

2. Que los mencionados oficios de fuera del regimiento deben ser repartidos a partes iguales entre los hombres de los regidores y los de los caballeros, escuderos y hombres buenos de la ciudad.

3. Que estos últimos también pueden dar los dichos oficios a hombres suyos, siempre que estén capacitados y reúnan los requisitos mencionados, siempre y cuando aquel que los nombrare sea el responsable pecuniario de los posibles delitos o infracciones de aquellas personas que recibiesen su nombramiento.

El último documento contenido en el Libro es la sentencia dada en el año 1452 por el entonces corregidor Alfonso de Estúniga, el cual se limita a confirmar la vigencia de todas las disposiciones contenidas en los documentos anteriores.

Desde este momento hasta la firma de la concordia de 1499 -toda la documentación que hemos manejado abunda en la idea-- lo más significativo son sin duda los autos de los pieitos emprendidos en 1485 por tal causa- de que durante los años finales del reinado de Enrique IV y buena parte del de los Reyes Católicos los regidores acapararán en sus manos muchas funciones que no les correspondian, marginando al resto

${ }^{9}$ AMZ. Libro Tumbo de las Escrituras..., fols. 89-101. Años 1342 a 1452. 
de los sectores ciudadanos y no respetando ni el espíritu ni la letra de los acuerdos que acabamos de ver ${ }^{10}$.

Es significativo que, todavia en $1494^{11}$, los reyes ordenen que se realice una información acerca de los oficios de la ciudad que antes disfrutaban caballeros e hidalgos de fuera del regimiento, oficios que - "después de los movimientos del reyno"- se repartían entre sí los regidores y los daban a quien querían.

Resulta de gran interés el análisis detallado de la concordia del año $1499^{12}$, en primer lugar porque viene a ser una especie de ordenanza o reglamento de funcionamiento interno de este grupo social; de hecho, alguna de las copias conservadas de esta concordia se titula precisamente así: "Ordenanzas del gremio de cavalleros e hijosdalgo.. En otro sentido, también es conveniente detenerse en ella porque permite constatar una evolución de la sociedad y las instituciones zamoranas similar, si bien con matices, a la de otras ciudades del reino ${ }^{13}$.

Un primer fenómeno que es constatable a primera vista es que los caballeros e hidalgos marginados del regimiento cuentan con capacidad suficiente para intervenir en la designación de los oficios concejiles, privilegio que viene de antiguo y que la instauración y posterior desarrollo del sistema de regidores no ha logrado desterrar, de forma tal que este grupo se nos presenta como un escalón intermedio, una "plataforma de ascenso social», hacia los puestos decisivos ocupados por la oligarquia de regidores.

Por otro lado, comprobamos que el regimiento vigente a finales del siglo $X V$ tiene ya muy poco que ver, después de ciento cincuenta años, con lo que era en sus origenes; no cabe duda de que los regidores han ido creciendo como grupo oligárquico autónomo al calor de la progresiva concentración en sus manos del poder municipal. De hecho, a finales del siglo $\mathrm{XV}$, el regimiento aparece controlado por un reducido grupo de fa-

to AGS. F.G.S. 19 y 22-XI-1485, fols. 106 y 99; 7-XII-1485, f. 108. AMZ. Leg. 19, doc. 23 (28-IV-1486). Son todos ellos documentos relativos a las quejas de los hidalgos por la no presencia de sus procuradores en las reuniones del consistorio. Vid. además $A G S$. Consejo Real, Leg. 49, F. 5\%, II, III, IV y $V$ sobre los pleitos de 1485.

"AGS. R.G.S. 16-XII-1494, f. 212.

12 Existen varias copias de la misma en el $A M Z$.: Leg. 11, doc. 5, y Leg. 15, doc. 4. La publicó C. Fernandez DuRo: Memorias Históricas de Zamora, su provincia y su obispado. Madrid, 1882. Tomo II, págs. 279-287.

${ }_{13} \mathrm{M}^{a}$ ASEnjo González, Segovia. La ciudad y su tierra a fines del Medievo. Segovia, 1986. (La cita corresponde a la edición de la Univ. Complutense), págs. 881-883. 
milias cuyos miembros, a veces dos o tres, son miembros activos del mismo.

El disfrute hereditario y la patrimonialización de las regidurias ha venido al cabo del tiempo a sustituir a un sistema más abierto, en el cual cabía una cierta rotación de las diferentes familias integrantes de una oligarquía más amplia en los puestos de regidores.

Un elemento que llama la atención y que ofrece diferentes interpretaciones es el hecho de que, a lo largo del último cuarto del siglo XV, algunas de las cabezas visibles del citado gremio de caballeros e hidalgos tiene lazos, en algunos casos muy estrechos, de parentesco con algunas de las familias que controlan el regimiento. Esto cabe interpretarlo en dos sentidos, o bien que se ha producido un desgajamiento en el seno de dichas familias, lo que no resulta demasiado verosímil, o bien que las familias que controlaban el regimiento, que insistimos son el escalón superior de la oligarquía urbana, ejercian también un relativo control sobre el resto del sector privilegiado de la ciudad ${ }^{14}$. En este sentido conviene recordar cómo en el siglo XVII algunos caballeros intentan conseguir la anulación de la concordia de 1499 alegando que ésta se produjo debido a los lazos de parentesco existentes entre algunos regidores $y$ algunos de los caballeros firmantes ${ }^{15}$.

Analicemos pues el contenido de la concordia. En primer término, es necesario destacar algunas frases previas a los acuerdos en las que, de una forma meridianamente clara, se nos proporciona una idea de la dimensión del enfrentamiento existente entre ambos grupos secularmente $y$, a la vez, de la trascendencia que para la vida y el gobierno de la ciudad tiene el acuerdo. Los representantes de los hidalgos señalan como "entre los dichos regidores de la dicha çibdad e los dichos cavalleros e escuderos e fidalgos della a grand tienpo que an tenido debate çerca de los ofiçios de la çibdad que en el consystorio se an de proveer e como quiera que con los regidores antepasados los dichos cavalleros e escuderos e fidalgos non pudieron concordarse e agora los regidores que a la saçon son acatando que los cavalleros e escuderos e fidalgos de la dicha çibdad son sus debdos e personas a quien se deve guardar toda onrra e faser gratificaçion an avido e an plaçer de se conçertar con ellos de les dar la mitad de los dichos ofiçios por la forma e manera que

${ }_{14}$ Por ejemplo, uno de los representantes elegidos por los hidalgos para negociar la concordia es Nuño Docampo que tiene parentesco muy cercano con los regidores Juan y Francisco Docampo.

15 E. Fernandez Prieto, obra citada, pág. 32 y siguientes. 
adelante dirá e los dichos cavalleros e escuderos e fidalgos de fuera del regimiento ansy les plaçe de reçibirlos".

El acuerdo consta de doce capítulos en los que, partiendo de una absoluta igualdad en el reparto de los oficios de elección, se regula meticulosamente todo lo relacionado con el proceso de selección y nombramiento de los citados oficiales del concejo y cargos de representación de la ciudad.

El primero de ellos pone de relieve la estructura un tanto jerarquizada de este grupo social; en efecto, presenta características similares a las de una organización gremial, esto no solamente lo evidencia, lo que ya de por sí casi sería suficiente, el propio nombre de gremio de caballeros, escuderos e hidalgos con el que se autodenominan. Existen referencias en los libros de actas del concejo de cómo cuando los regidores ordenan convocar a los representantes de los gremios, los caballeros acuden como uno más. Por otra parte, su funcionamiento es parecido: la asamblea elige a cuatro caballeros «nombradores" que serán los encargados de la presentación para su nombramiento en consistorio, mediante los sistemas que más adelante veremos, de los hidalgos que desempeñarán los diferentes oficios.

Los oficios que requerían la presencia de un hidalgo desempeñándolo eran los siguientes:

- Procuradores en Cortes (uno).

- Jueces de alcaldías ordinarias.

- Alcaldía de Hermandad (una).

- Mensajerias a la Corte y a otros lugares.

- Fieles de las Carnes.

- Fieles de las Calles.

Los cuatro representantes, o más concretamente administradores, del gremio eligen a un número determinado de hidalgos, variable según los oficios de que se trate: ocho personas para procuradores en Cortes, cinco para la alcaldía de Hermandad, seis para mensajerías y 10 para fieldades, posteriormente se sorteaban los cargos entre los designados.

En otro orden de cosas, también es perceptible con cierta claridad el hecho de que sobre esta elección se cierne la posibilidad de un veto encubierto por parte de los regidores, ya que éstos siempre tenían la facultad de desechar a uno de los elegidos mediante la justificación, un tanto imprecisa, de que actuaban de ese modo por "pro e onrra de la dicha çibdad». 
Los regidores, por su parte, disfrutan de una situación de privilegio considerable a la hora de designar personas para los oficios que a ellos les corresponden, de forma tal que podian nombrar a cualquiera de sus escuderos o criados, algo que naturalmente la facilitaba un control mucho más directo de todos los escalones de la administración ciudadana. También tenían la posibilidad de designar a cualquier hidalgo de fuera del regimiento para un determinado oficio, lo cual no supone que el citado hidalgo se vea obligado a renunciar a su turno en los nombramientos hechos por su gremio; parece pues que la representación de los hidalgos en los diferentes cargos estaba en cierta medida pactada, de manera tal que los irian ocupando por riguroso turno, según parece confirmarlo otro de los capítulos de la concordia ${ }^{16}$. Pero, al margen de esto, la idea que resalta al constatar las amplias facultades que poseen los regidores, es que pueden utilizarlas como mecanismo para la atracción de determinados hidalgos o familias hacia la esfera de influencia de alguno de los clanes fuertemente asentados en el regimiento, a los que indudablemente interesaba contar con una sólida clientela como soporte de su poder en el seno de la comunidad.

Otra de las cláusulas del acuerdo especifica que los cargos unipersonales debian ser desempeñados alternativamente cada año por los nombrados por una y otra parte, es el caso de la vara de la Alcaldía de la Hermandad, si bien este cargo tiene sus peculiaridades. Por otro lado, los hidalgos designados para el desempeño de un determinado oficio debian hacerlo por sí mismos, sin la posibilidad de poder delegar en otro miembro del gremio, salvo en caso de ausencia obligada de la'ciudad o enfermedad, casos en los que el sustituto no perdía el turno para ser elegido con posterioridad.

Algunos otros capitulos nos hacen avanzar en la comprensión de la organización y estructura de los caballeros e hidalgos entendidos como grupo. Asi, los cuatro representantes elegidos un año tienen la prerrogativa y la obligación de designar a sus sucesores para el año venidero, lo que sin duda viene a significar una posición de cierto privilegio de algunas familias o linajes que se situarian a la cabeza del grupo social de un modo casi hereditario.

${ }^{16}$ En la Concordia: “Item que los dichos nonbradores no pongan en los tales nonbramientos al cavallero o fidalgo que una ves oviere el ofiçio o cargo para el que fuere nonbrado fasta en tanto que los otros fidalgos e buenos gosen para que todos puedan aver onrra e provecho". 
Esta situación de privilegio parece confirmarse si contemplamos otras cláusulas del acuerdo en las que aparecen elementos correctores que posibilitan una cierta igualdad, o al menos aspiran a lograrla, entre todos los hidalgos a la hora de ser designados para un oficio; en este sentido, la cláusula número 10 apunta las intenciones de los caballeros en tal sentido: «nos pareçe que por no aver igual los linages basta para aver los ofiçios susodichos deve bastar que aviendo en la dicha çibdad personas que biban en onrra e ábito de fidalgos que puedan ser nonbrados e gosar de los dichos ofiçios el tienpo que les copiere".

Ya hemos señalado más arriba algunos apartados que ponen de manifiesto ciertos privilegios de los regidores que apuntalan considerablemente el férreo control que ejercen sobre el gobierno municipal; otro elemento que viene a confirmar esta situación es el hecho de que los hidalgos que desempeñan el oficio de fiel en todo momento estaban supeditados a las decisiones de los dos regidores que actúan como sobrefieles, de tal manera que en caso de existir discrepancias con alguna decisión de éstos por parecerles injusta o con alguna de las normas emanadas del consistorio, su reclamación debía presentarse al conjunto de los regidores, siéndoles negada la posibilidad de acudir al corregidor $u$ otro oficial real presente en la ciudad. Constatamos pues el intento de los regidores por delimitar y definir aquellos aspectos de la vida ciudadana cuya responsabilidad y gestión les correspondia en exclusiva, procurando evitar la intromisión en ellos de los oficiales reales.

Las actas de las reuniones del consistorio del año 1502 nos proporcionan un excelente ejemplo de lo que acabamos de señalar. En la sesión del 1 de abril se acuerda introducir una modificación en la ordenanza del pescado en el sentido de que los fieles de las carnes no pongan el pescado en la red sin previamente mostrarlo a los regidores, bajo pena de 600 maravedies y pérdida del oficio. En la sesión siguiente, día 4, se aquilata aún más el contenido de la nueva disposición, señalando la obligación de los fieles de ir a buscar a su casa al sobrefiel y, en caso de que éste no estuviera, autorizándoles a poner el pescado en la red, siempre y cuando luego pasase el sobrefiel a verlo. En la sesión del día 6 los regidores indican a los fieles de las carnes de los hidalgos la obligación de jurar la nueva ordenanza so pena de perder los oficios, éstos replican que o se revoca la ordenanza o entablarían pleito ante sus altezas, los regidores solicitan que se lo manifiesten por escrito, cosa que los fieles de hidalgos realizan en la sesión siguiente del día 8 de abril. En la misma sesión los procuradores del común y de la tierra manifiestan su apoyo al regimiento y su aceptación de la nueva ordenanza. En la sesión del día 11 los regidores se reafirman en su postura y asi se lo hacen saber a 
los hidalgos. En las sesiones de los días 15 y 18 se produce el desenlace de esta lucha, que por su duración podría llamarse «batalla de los diez días", con el juramento de la nueva ordenanza por parte de Lorenzo Docampo y Francisco de Trujillo, fieles de las carnes de los hidalgos. No parecen precisos más comentarios ante la evidencia del rotundo fracaso cosechado por los hidalgos en esta, pequeña pero significativa, prueba de fuerza con los regidores.

Lo dicho hasta ahora nos aproxima al conocimiento del eje básico de la evolución del gobierno ciudadano, fundamentado en las relaciones que se establecen entre los distintos sectores de la oligarquía, regidores y caballeros, unas veces en conflicto y otras en aparente armonia, pero que, en la práctica, son los que se reparten, bajo el predominio de los primeros, el poder político y económico en el seno de la comunidad urbana. 